\title{
IMPLICAÇÕES DINÂMICAS PARA A FORMAÇÃO DA FONOLOGIA EM L2
}

Reiner Vinicius Perozzo ${ }^{1}$

Ubiratã Kickhöfel Alves²

\begin{abstract}
RESUMO
Neste artigo, discutimos a formação do componente fonético-fonológico de L2 a partir de uma concepção dinâmica. Frente a esse objetivo, propomos uma exposição dos principais aspectos da concepção emergentista de aquisição de linguagem, o que possibilitará uma discussão sobre os pressupostos de uma visão com base na Teoria dos Sistemas Dinâmicos para o entendimento do processo de aquisição de linguagem. Com base na apresentação desses postulados, discutimos a percepção e a produção dos sons da L2 a partir da visão dinâmica. Por fim, discutimos as implicações desta perspectiva para a pesquisa em aquisição fonético-fonológica, bem como para o próprio ambiente de ensino de L2, focalizando os principais desafios impostos por essa concepção.
\end{abstract}

Palavras-chave: Aquisição fonético-fonológica de L2. Emergentismo. Teoria dos Sistemas Dinâmicos.

\section{INTRODUÇÃO}

O presente artigo trata da relação entre o processo de formação do componente fonético-fonológico ${ }^{3}$ da $\mathrm{L}^{4}$ e uma abordagem dinâmica para a constituição do conhecimento. Tendo em vista que a perspectiva dinâmica para a aquisição de L2 é relativamente recente e propõe a quebra de alguns tabus, faz-se necessário que tracemos uma perspectiva de cunho emergentista, com o objetivo de explicar como tal perspectiva concebe 0 processo de aprendizagem e desenvolvimento linguístico. A segunda seção aborda o processo de aquisição de L2 a partir de uma perspectiva mais dinâmica, levando em consideração a confluência de inúmeras variáveis que atuam na instanciação do conhecimento da nova língua. 
$\mathrm{Na}$ terceira seção, tais pressupostos dinâmicos são aplicados, especificamente, às questões referentes ao componente fonético-fonológico da L2. Finalmente, ao concluirmos o trabalho, apresentamos algumas considerações que retomam 0 escopo da base dinâmica para a aquisição do conhecimento linguístico, de modo a promovermos uma reflexão acerca das implicações e desafios impostos por tal perspectiva, tanto para o contexto de pesquisa linguística, quanto para o ambiente de ensino.

\section{AQUISIÇÃO DA LINGUAGEM E O DESENVOLVIMENTO DA LÍNGUA ESTRANGEIRA - UMA PERSPECTIVA EMERGENTISTA}

Em modelos que veem o processo de aquisição de linguagem sob uma perspectiva emergentista, embora haja inegáveis diferenças entre a aquisição da língua materna e a aquisição da língua estrangeira, diversas estratégias e mecanismos - não exclusivamente de natureza puramente linguística (contrariando, portanto, o advogado pela escola gerativista) - são utilizados pelos falantes de modo a internalizarem o sistema de comunicação.

Tanto na língua materna como na língua estrangeira, nosso aparato cognitivo desempenha inúmeras tarefas que nos garantem a aquisição da linguagem. Ao considerarmos que tal processo é um fenômeno psicolinguístico por excelência ( $\mathrm{N}$. ELLIS, 2005), a aquisição da linguagem não pode ser vista através de uma teoria somente linguística, pois essa, por si só, não dá conta de englobar as diversas outras variáveis que estão em jogo. Neste sentido, traz-se à tona a concepção emergentista de aquisição de linguagem, em que a aprendizagem da língua materna e da língua estrangeira é baseada na construção de padrões associativos, os quais são reforçados a partir de efeitos de frequência e da recência com que ocorrem ( $N$. ELLIS, 2005). Tal perspectiva assume que, quanto mais frequente e recente é o padrão observado, mais robusto ele se torna.

O aprendiz de segunda língua, assim como o faz na língua materna, extrai regularidades do input a que está exposto. Assim, a aprendizagem é estatística e é desenvolvida sobre a experiência com a linguagem (ELLIS, 2005; ZIMMER; SILVEIRA; ALVES, 2009; ZIMMER; ALVES, 2012). Conjuntamente, o input que nos cerca é necessariamente rico e veicula detalhes suficientes para que possamos nos utilizar da linguagem (CHRISTIANSEN; ALLEN; SEIDENBERG, 1998). 
Um aspecto importante a ser enfatizando é o fato de que o emergentismo trata o conhecimento linguístico como qualquer outro conhecimento, sem a necessidade de uma faculdade da linguagem ou módulo específico para ela. Dessa maneira, o conhecimento que temos da habilidade de andar de bicicleta, de caminhar e de dirigir, por exemplo, é instanciado do mesmo modo que o conhecimento das habilidades linguísticas - através de associações cognitivas, quantidade suficiente de exposição e fatores como frequência, recência e saliência do estímulo. Obviamente, os diversos tipos de conhecimento são de diferentes níveis, havendo, assim, conhecimentos mais simples e conhecimentos mais complexos e elaborados, que se encontram em constante interação frente à aquisição de um novo conhecimento. É ressaltado, assim, o papel fundamental do conhecimento prévio na aquisição.

Em outras palavras, a exemplificação acima apresentada demonstra o dinamismo da aquisição de aspectos linguísticos da segunda língua. É importante mencionar que a constante relação dinâmica entre esse novo conhecimento e vivências prévias do aprendiz com aspectos associados ao contato com este item linguístico. Ressaltam-se, assim, as percepções do aprendiz, os sentimentos, as memórias das vivências em que os itens linguísticos foram utilizados, dentre muitos outros. Enfim, a aquisição é influenciada por uma grande variedade de conhecimentos prévios e por diferentes fatores, de modo a constituir tarefa impossível, na verdade, determinar todos os aspectos e variáveis efetivamente em jogo na aquisição de um determinado item linguístico. É a partir desse cenário que podemos pensar em uma perspectiva dinâmica de aquisição de linguagem, conforme será visto no que segue.

\section{A AQUISIÇÃO E O DESENVOLVIMENTO DA FONOLOGIA SOB O PRISMA DINÂMICO}

A cada dia experienciamos coisas novas, temos acesso a diferentes elementos do universo, vemos pessoas que nunca vimos antes e também desenvolvemos novas sensações e percepções. A mudança é parte de nossas vidas: passamos por um grande ciclo que possui um início e um final. Ao longo dos anos, acumulamos experiência, conhecimento de mundo, estabelecemos relações sociais, somos influenciados por diversas variáveis e também influenciamos outros 
seres. Usamos um tipo de roupa específico em eventos de gala e outro completamente diferente quando organizamos a casa ou o escritório. Falamos de diferentes maneiras dependendo do nosso interlocutor e nos comportamos de modo distinto dependendo da situação em que nos encontramos.

Assim como nossa personalidade evolui e nossas vidas se modificam em diferentes situações e com o passar do tempo, a nossa língua também evolui e se apresenta em constante mudança. Tal é o processo de formação e desenvolvimento do léxico, da fonologia, da morfologia e da sintaxe, por exemplo: não linear e complexo, imbuído de inúmeras variáveis, não necessariamente caracterizadas como puramente linguísticas (como fazia o paradigma gerativista), que estão sempre em atividade e se modificando.

Antes de tratar, propriamente, da aquisição e do desenvolvimento do componente fonético-fonológico da língua estrangeira, é imprescindível que tenhamos em mente uma noção geral de como a linguagem é vista sob a ótica dinâmica. Tal perspectiva, que concebe a aquisição da linguagem como processo emergente (e, portanto, leva em consideração os pressupostos já explicitados na seção anterior), trata de abordar a aquisição do conhecimento como processo em incessante evolução, afetando e sendo afetado por, em maior ou menor grau, todos os componentes do sistema cognitivo.

A Teoria dos Sistemas Dinâmicos (TSD) surge na área da matemática para tentar explicar o comportamento de sistemas complexos e dinâmicos. Uma vez que a linguagem é, por excelência, um organismo complexo e dinâmico, diversos autores mostram-se a favor da aproximação dos estudos linguísticos à TSD (BYBEE, 2006, 2010; DE BOT; LOWIE; VERSPOOR, 2007; VAN GEERT, 2007; LARSENFREEMAN, 2011). De acordo com De Bot, Lowie e Verspoor (2007), a TSD parece ser uma abordagem coerente para dar conta da linguagem porque considera tanto aspectos linguísticos como sociais. Ao aplicarem a TSD à linguagem, De Bot, Lowie e Verspoor (2007) ilustram que diversas variáveis operam de maneira conjunta no desenvolvimento da língua materna/estrangeira, e que mudanças em uma variável, por menores que sejam, podem impactar todas as outras do sistema. Os autores afirmam que cada sistema é parte de outro sistema, imbuídos de princípios atuantes em todos os níveis.

Os sistemas dinâmicos, para De Bot, Lowie e Verspoor (2007), parecem ser profundamente influenciados pelos seus estágios iniciais, em que pequenas 
diferenças podem causar um enorme efeito ao longo de seu percurso. Nesse sentido, está presente a não linearidade entre o período inicial e as proporções da mudança no sistema. Segundo os pesquisadores, os significados não são transmitidos linearmente através de um transmissor e um receptor, mas são coconstruídos no sistema. Os autores destacam que, em função de os sistemas estarem em fluxo constante, é natural e esperado que eles apresentem variações, tornando-os sensíveis a um determinado input em certo espaço de tempo e a outro input em outro espaço de tempo. Os modelos dinâmicos olham justamente para a relação entre variáveis e comportamentos e também como tal relação se organiza ao longo do tempo.

Um conceito fundamental na TSD é o que se conhece como atrator. Sob a ótica de De Bot, Lowie e Verspoor (2007), os subsistemas dinâmicos parecem se estabelecer em estados específicos - os estados atratores - que são preferidos, mas não necessariamente previsíveis. A força magnética que um imã exerce sobre um pequeno pedaço de ferro, por exemplo, representa um estado atrator. Entretanto, a força magnética que um imã exerce sobre outro ímã representa um estado repelidor ${ }^{5}$. Assim, estados repelidores são claramente não preferidos nos subsistemas.

Quanto à necessidade de um aparato inato para a linguagem, uma vez que se enquadra sob uma perspectiva emergentista, a TSD não considera a existência de um dispositivo específico, porque a complexidade e a criatividade na língua emergem de iterações. Sob este enfoque, Smith, Kirby e Brighton (2003) defendem que a aquisição da linguagem não está livre de enviesamento, mas que o enviesamento não é necessariamente específico e direcionado para a linguagem. De acordo com estes autores, a linguagem enquanto sistema dinâmico é transmitida culturalmente, em que o output de um indivíduo funciona como input para outro indivíduo, e este processo iterativo, elementarmente social, faz com que o conhecimento linguístico ocorra.

Van Geert (1995), ao tratar da TSD, faz menção a um termo bastante importante, o crescimento. Para o pesquisador, o crescimento tem a ver com o aumento positivo ou negativo da aprendizagem e está condicionado a recursos internos e externos. Recursos internos seriam capacidade de aprendizagem, tempo de aprendizagem, memória e motivação, enquanto que recursos externos estariam ligados a espaços para exploração do conhecimento, linguagem, ambiente e 
materiais didáticos. Para o pesquisador, tais recursos são limitados e interconectados e, nesse sentido, ressalta-se que um recurso pode vir a compensar a falta de outro, como, por exemplo, o esforço (recurso interno) pode compensar a falta de tempo (recurso externo), ou mesmo a motivação pode compensar um input mais limitado.

Em termos de aprendizagem, Van Geert (1995) afirma que nem todos os subsistemas demandam a mesma quantidade de recursos e que, inclusive, um pode otimizar o outro. O autor aponta como exemplo o desenvolvimento lexical e o desenvolvimento da compreensão auditiva. Seguindo seu raciocínio, Van Geert (1995) explana que, com o aumento da compreensão auditiva, as palavras são mais facilmente entendidas e interpretadas, implicando o desenvolvimento de habilidades lexicais. Paralelamente, ao se estimular o espaço lexical, a compreensão auditiva se torna mais acessível. Ou seja, um recurso alimenta o outro.

De maneira geral, De Bot, Lowie e Verspoor (2007) concebem o aprendiz como um subsistema dinâmico dentre um sistema social, e é regido por outros "subsubsistemas" operantes. Além disso, o aprendiz é dotado de um ecossistema cognitivo (intencionalidade, cognição, inteligência, motivação, aptidão, dentre outros) que está intimamente ligado ao que o cerca (linguagem, nível de escolaridade, poder aquisitivo), que por sua vez se relaciona ao ecossistema social, imbuído de suas inúmeras variáveis.

Larsen-Freeman (2011, p. 4) elenca, de maneira bastante elucidativa, algumas características gerais da TSD que nos podem ser úteis. Resumidamente, para a estudiosa, os sistemas dinâmicos:

- São abertos e se adaptam através de interação com o ambiente e por meio de organização interna/auto-organização;

- Operam em condições de não equilíbrio;

- Compreendem muitos agentes ou elementos, os quais interagem entre si;

- Dispõem de forças de interação que se modificam ao longo do tempo;

- São operacionalizados de maneira complexa a partir da atividade de seus componentes;

- Iteragem continuamente, sendo que um determinado nível de desenvolvimento é necessariamente dependente de um nível predecessor. 
Conforme podemos compreender, os sistemas dinâmicos se configuram a partir de inúmeras variáveis, as quais são de distintas naturezas. A aquisição da fonologia, assim como a da morfologia e de outros subsistemas da linguagem (que também é um sistema existente entre outros) respeita e segue a premissa de uma constelação de variáveis em jogo. Entende-se que a linguagem é construída sobre unidades cognitivas, sociais, linguísticas, ambientais, comportamentais, dentre muitas outras, que são representadas através de variáveis a serem consideradas.

Sobretudo no caso de aquisição fonético-fonológica de língua estrangeira, devemos lembrar que, além dos fatores já mencionados, a quantidade e a qualidade do input, linguístico ou não, são basilares para a instanciação do componente sonoro. Com base na TSD, constatamos que a aquisição fonético-fonológica vai muito além de um conjunto de regras a ser aprendido e transcende a noção de acesso a um componente especializado unicamente à linguagem. Tal concepção dinâmica ficará mais clara no que segue.

\section{PENSANDO A AQUISIÇÃO FONÉTICO-FONOLÓGICA DE L2 SOB UMA PERSPECTIVA DINÂMICA}

Conforme visto na seção anterior, uma perspectiva dinâmica leva em consideração uma grande quantidade de variáveis para explicar a emergência dos sistemas linguísticos. Isolar essas variáveis mostra-se como uma tarefa praticamente impossível, visto que o dinamismo do processo de aquisição pode estar sofrendo efeitos de entidades que nem tampouco o pesquisador consegue identificar e controlar. Independente de quantas e quais são as variáveis em jogo, é indiscutível que o sistema de L2, a própria L1 do aprendiz, o contexto de aprendizagem, o grau de atenção, a idade, a motivação e a aptidão, bem como diversas outras variáveis já apontadas pela literatura (ELLIS, 2005, 2006, 2011; SEVILLE-TROIKE, 2006; ORTEGA, 2009; ZIMMER; SILVEIRA; ALVES, 2009) exercem efeito nesse complexo processo.

Concentrando-nos, especificamente, no caso da aquisição do componente fonético-fonológico da $L 2$, vemos que tal perspectiva ressalta o caráter funcional das pistas acústicas presentes na cadeia de som da língua a ser adquirida. Nesse sentido, o sistema de L1 exerce papel fundamental, de modo a atuar tanto na percepção quanto na produção dos novos sons a serem adquiridos para a distinção 
de significados na nova língua. Cai por terra, assim, a concepção de fonema como ente abstratamente desassociado do componente físico da cadeia sonora - a aquisição implicará o papel de diferentes pistas acústicas, agindo conjuntamente para a distinção dos significados. Adquirir os sons da língua estrangeira implica saber focalizar aquelas pistas acústicas que se mostram mais fundamentais para a distinção de significados na L2.

No que diz respeito à questão da percepção dos sons da língua-alvo, um modelo perceptual que se mostra de acordo com uma concepção dinâmica de aquisição fonético-fonológica é o Perceptual Assimilation Model-L2 (BEST; TYLER, 2007). Tal proposta tem por base o modelo de Fonologia Gestual de Browman e Goldstein (1992, 1993, 2000), que adota o gesto fonológico, de natureza dinâmica, como primitivo de análise. Conforme explicam Antoniou et al. (2011), a proposta de Best e Tyler (2007) prevê que as categorias fonológicas da língua-alvo podem ser formadas a partir de uma ou mais pistas fonéticas, tomadas como primordiais para a formação da representação gestual e, por conseguinte, para as distinções funcionais entre os sons. Assim, de acordo com a perspectiva postulada no PAM-L2, os novos sons da língua-alvo podem ser "assimilados" de acordo com os padrões da $L 1$, de modo que os gestos da L2 podem ser interpretados como formações gestuais de fonemas já existentes no espaço fonético-fonológico da língua materna do aprendiz. É preciso, portanto, que o aprendiz consiga, através da busca pelas pistas acústicas diferenciais, estabelecer distinções entre as formações gestuais da L1 e da L2, bem como ser capaz de determinar, com base no uso linguístico, as implicações funcionais dessas diferenças entre os fones físicos.

É importante dizer que, ainda que a percepção das diferenças gestuais entre língua-fonte e língua-alvo seja um pré-requisito para o estabelecimento das diferenças funcionais na $L 2$, tal capacidade não se caracteriza como condição suficiente para a produção efetiva dos sons da língua-alvo. Conforme explicam Zimmer e Alves (2012), adquirir o sistema fonético-fonológico da L2 implica saber orquestrar múltiplos articuladores, de forma dinâmica, de acordo com o ritmo e a cadência da língua-alvo, para que as distinções funcionais sejam estabelecidas através do uso eficiente das múltiplas pistas acústicas vigentes no sistema-alvo. Tal tarefa não necessariamente representa uma atividade fácil, uma vez que o sistema da L1 constitui em termos dinâmicos, uma espécie de atrator que tende a levar a produção no novo sistema linguístico àquelas formações gestuais vigentes na língua 
materna. É preciso, portanto, estabelecer novos sistemas de atratores, de modo que seja adquirida a nova sintonia dos diversos articuladores, agindo em conjunto, sob a cadência da L2. Nesse sentido, adquirir a fonologia da nova língua, sob essa perspectiva, unifica as noções segmentais e suprassegmentais, pois a efetiva aquisição implica, necessariamente, o domínio dos padrões de temporalidade do sistema-alvo, temporalidade essa que é o item-chave de qualquer sistema dinâmico.

Em suma, a aquisição fonético-fonológica de L2 constitui um processo complexo, influenciável e influenciador das mais diferentes variáveis, que atuam em conjunto na aquisição do conhecimento, tanto em termos de percepção, quanto de produção, da temporalidade da língua, em busca de seus aspectos primordialmente funcionais. Ao considerarmos toda essa complexidade, mais do que soluções, uma série de questionamentos e desafios vêm à tona. No que segue, refletiremos sobre tais desafios.

\section{CONSIDERAÇÕES FINAIS: IMPLICAÇÕES E DESAFIOS DE UMA CONCEPÇÃO DINÂMICA DE AQUISIÇÃO FONÉTICO-FONOLÓGICA DE L2}

Com tantas variáveis operando em conjunto, e estas somadas a muitas outras não aqui nomeadas, faz-se lógico pensar que uma teoria puramente linguística não dê conta de descrever e explicar o processo de aquisição e desenvolvimento de uma língua estrangeira. É justamente nesse aspecto que reside o grande mérito da TSD, pois ela reconhece e equipara, em termos de influência no sistema, variáveis linguísticas, sociais, cognitivas e comportamentais.

Um novo paradigma no que tange à aquisição (fonético-fonológica) de língua estrangeira toma forma a partir da TSD. É evidente que, como todas as teorias, a TSD tem suas limitações e pontos a serem ainda resolvidos. No entanto, julgamos que a TSD é um modelo que torna esse gigantesco universo da L2 mais tangível aos nossos olhos e mais concreto quanto aos fatores que realmente estão em jogo no caminho da aquisição dos subsistemas da linguagem.

Por outro lado, os desafios a serem enfrentados, não somente no que diz respeito à investigação científica do complexo processo de aquisição, mas, também, no que concerne ao próprio ambiente de ensino de línguas, adquirem uma proporção ainda maior, vista a infinita gama de possibilidades apresentada por um sistema dinâmico em meio a uma mudança de direcionamento. Nesse sentido, ao 
encerrarmos este trabalho, propomos uma reflexão acerca das implicações de uma concepção dinâmica sob estes dois âmbitos, referentes, respectivamente, aos universos de pesquisa e ensino.

No que diz respeito ao âmbito dos estudos linguísticos, mais especificamente no que diz respeito à investigação do processo de aquisição de L2, um constante questionamento diz respeito a como se pode "controlar" todas as variáveis envolvidas no processo de aquisição. Antes mesmo de que sejam feitas considerações acerca dessa questão, julgamos necessário, primeiramente, deixar claro que, sob a perspectiva dinâmica, o foco do estudo de aquisição deixa de ser o resultado, mas passa a ser toda a trajetória desenvolvimental dos aprendizes investigados. Em outras palavras, uma perspectiva dinâmica, caracterizada pelo movimento, pela temporalidade e pela progressão, deve voltar-se ao estudo de toda a curva desenvolvimental do aprendiz, de seus progressos, de seus retrocessos, e de possíveis explicações dessa caminhada.

Assim, parece-nos que fica claro o fato de que, apesar de todo um rigor metodológico, nunca todas as variáveis serão plenamente "controladas", conforme advogado por outras perspectivas de aquisição. Ainda que um rigor científicometodológico se faça fundamental, múltiplas variáveis, muitas das quais nem tomamos conhecimento, estão em jogo, o que torna impossível controlar todos os fatores em voga no processo. Fica clara, também nesse sentido, a importância de uma visão individualizada para as diferentes trajetórias desenvolvimentais de cada aprendiz, uma vez que cada participante traz uma diferente bagagem cognitiva, diferentes saberes, bem como experiências, diferentes sensações e efeitos, frente a novos conhecimentos. Em suma, mais do que um olhar para o produto final, é pertinente um olhar mais individualizado para a trajetória, de modo que tentemos discutir e chegar a uma aproximação das diversas variáveis que estão em jogo no processo de aquisição de cada aprendiz.

É essa diferença de orientação que nos permite pensar, também, sobre desafios para o próprio ambiente de aprendizagem de línguas. No que diz respeito ao componente fonético-fonológico da $L 2$, a produção com sotaque é vista como efeito de um processo cuja complexidade, ainda que venha a incluir, implica muito mais do que uma pura transferência entre os sistemas da L1 e da L2. Mais do que isso, as considerações aqui feitas contribuem para um entendimento não somente de tal aspecto linguístico, mas, também, para o próprio entendimento do todos os 
componentes formais da língua estrangeira. Tal perspectiva de aquisição multimodal do conhecimento implica uma busca pelo entendimento ainda maior das individualidades do aprendiz, bem como tenta vê-lo em sua totalidade, de modo que fatores sociais, emocionais e cognitivos não sejam desassociados.

Em termos de ensino, essa nova perspectiva exige uma associação entre diferentes áreas de conhecimento, uma vez que a noção fragmentada de conhecimento não condiz com uma perspectiva de acordo com a qual os múltiplos saberes se reforçam e colaboram para as mudanças do sistema complexo. No que diz respeito ao ensino de L2, não há espaço para uma abordagem descontextualizada, ou até mesmo fragmentada, entre os componentes linguísticos - o ensino de pronúncia deve ser, portanto, vinculado às propriedades funcionais da língua, de forma associada a todos os aspectos do sistema-alvo. Em outras palavras, não existe mais espaço, portanto, para aulas de "gramática", "vocabulário" ou "pronúncia", de forma desvinculada. De fato, tal vinculação deve ir além dos componentes do sistema linguístico: uma perspectiva dinâmica ressalta a importância de associar não somente os diferentes módulos de conhecimento, mas, também, de associar o conhecimento à própria vivência do aprendiz.

As considerações acima feitas podem representar, de fato, um aspecto amedrontador a vários investigadores e profissionais da linguagem, uma vez que deixam claro o fato de que, independentemente dos cuidados metodológicos a serem tomados pelos investigadores, um quadro claro de todas as variáveis em jogo no processo de aquisição de um único aprendiz não se faz impossível. Ainda que, a uma primeira vista, tal quadro possa parecer desmotivador, consideramos que tal constatação, na verdade, abre portas para um entendimento do indivíduo como ser altamente complexo. Sendo também complexos os processos cognitivos pelos quais passam tais indivíduos, processos esses dentre os quais se destaca a aquisição do conhecimento de uma L2, entendemos, com maior clareza, toda a riqueza dessa caminhada, bem como as suas implicações para o desenvolvimento do indivíduo e do próprio ambiente. Dessa forma, ao mesmo tempo em que os pressupostos dinâmicos intensificam os desafios a serem enfrentados, é possibilitado, por tal perspectiva, um maior entendimento do indivíduo em sua totalidade. 


\title{
NOTAS
}

${ }^{1}$ Doutorando em Linguística Aplicada. Programa de Pós-Graduação em Letras. Universidade Federal do Rio Grande do Sul.

${ }^{2}$ Professor do Programa de Pós-Graduação em Letras. Universidade Federal do Rio Grande do Sul. Bolsista de Produtividade em Pesquisa - CNPq - Nível 2.

${ }^{3}$ Neste trabalho, utilizamos o termo 'fonético-fonológico' para dar conta de uma concepção de fonologia dinâmica, de acordo com a qual o fone físico constitui a evidência para as distinções funcionais da língua, sem que haja uma visão dicotômica entre os construtos tradicionais de 'fonética' e 'fonologia' (ZIMMER; ALVES, 2006, 2012).

${ }^{4}$ Neste trabalho, não estabelecemos diferença entre os termos 'Segunda Língua' (L2) e Língua Estrangeira (LE).

${ }^{5}$ Do inglês, repeller.

\section{IMPLICATIONS FROM A DYNAMIC VIEW ON L2 PHONETIC-PHONOLOGICAL ACQUISITION}

\begin{abstract}
In this article, we discuss the process of $L 2$ phonetic-phonological acquisition from a dynamic account. We present an overview of emergentism, which will pave the way for a discussion on the tenets of Dynamic Systems Theory in language acquisition. Based on these tenets, we discuss the perception and production of L2 sounds under a dynamic view. Finally, we discuss the implications brought up by this dynamic account on the research and teaching scenarios, by highlighting the main challenges presented by this account.
\end{abstract}

Keywords: L2 Phonetic-Phonological Acquisition. Emergentism. Dynamic Systems Theory.

\section{REFERÊNCIAS}

ANTONIOU, M.; BEST, C. T.; TYLER, M. D.; KROOS, C. Inter-language interference in VOT production by L2-dominant bilinguals: asymmetries in phonetic codeswitching. Journal of Phonetics, v. 39, p. 558-570, 2011. 
BEST, C. T.; TYLER, M. Nonnative and second-language speech perception: commonalities and complementarities. In: BOHN, O. S.; MUNRO, M. J. (Orgs.). Language experience in second language speech learning: in honor of James Emil Flege. Philadelphia: John Benjamins Publishing Company, 2007, p. 13-34.

BROWMAN, C. P.; GOLDSTEIN, L. Articulatory phonology: an overview. Phonetica, v. 49, p. 155-180, 1992.

. Dynamics and articulatory phonology. In: VAN GELDER, T; PORT, R. F. (Eds.). Mind as motion. Cambridge, MA: MIT Press, 1993, p. 51-62.

. Competing constraints on intergestural coordination and self-organization of

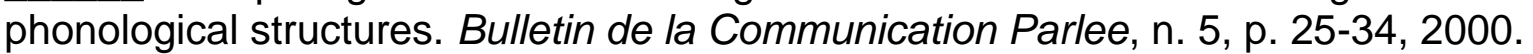

BYBEE, J. From usage to grammar: the mind's response to repetition. Language, v. 82 , n. 4, p. 711-733. 2006.

2010.

. Language, usage and cognition. New York: Cambridge University Press,

CHRISTIANSEN, M.; ALLEN, J.; SEIDENBERG, M. Learning to segment speech using multiple cues: a connectionist model. Language and Cognitive Processes. v. 13, p. 221-268, 1998.

DE BOT, K.; LOWIE, W.; VERSPOOR, M. A dynamic systems theory approach to second language acquisition. Bilingualism, Language and Cognition, v. 10, n. 1, p. 7$21,2007$.

ELLIS, N. At the interface: dynamic interactions of explicit and implicit language knowledge. Studies in Second Language Acquisition, v. 27, p. 305-352, 2005.

ELLIS, N. The Associative-Cognitive CREED. In: PATTEN, B. V.; WILLIAMS, J. (Eds.). Theories in second language acquisition: an introduction. Mahwah: Lawrence Erlbaum Associates, 2006. p. 77-96.

ELLIS, N. The emergence of language as a complex adaptive system. In: SIMPSON, J. (Ed.). The routledge handbook of applied linguistics. Abingdon: Taylor \& Francis Group, 2011. p. 654-667.

ELLIS, R. Principles of instructed second language acquisition. CAL Digest. p. 1-6, 2008.

LARSEN-FREEMAN, D. Complex, dynamic systems: a new transdisciplinary theme for applied linguistics? Language Teaching, Plenary Speech, 2011.

ORTEGA, L. Understanding second language acquisition. Londres: Hodder Education, 2009.

SAVILLE-TROIKE, M. Introducing Second Language Acquisition. New York: Cambridge University Press, 2006. 
SCHACHTER, J. Testing a proposed universal. In: GASS, S.; SCHACHTER, J. (Eds.) Linguistic perspectives on second language acquisition. Cambridge: CUP, 1989, p. 73-88.

SAVILLE-TROIKE, M. Introducing second language acquisition. New York: Cambridge University Press, 2006

SMITH, K.; KIRBY, S.; BRIGHTON, H. Iterated learning: a framework for the emergence of language. Artificial Life, n. 9, p. 371-386, 2003.

VAN GEERT, P. Dimensions of change: a semantic and mathematical analysis of learning and development. Human Development, v. 38, p. 322-331, 1995.

VAN GEERT, P. Dynamic systems in second language learning: some general methodological reflections. Bilingualism, Language and Cognition, v. 10, n. 1, p. 4749, 2007.

ZIMMER, M. C.; ALVES, U. K. A produção de aspectos fonéticos/fonológicos da L2: instrução explícita e conexionismo. Linguagem \& Ensino, v. 9, n. 2, p. 101-143, 2006.

. Uma visão dinâmica da produção da fala em L2: o caso da dessonorização terminal. Revista da Abralin, v. 11, n. 1, p. 221-272, 2012.

ZIMMER, M. C.; SILVEIRA, R.; ALVES, U. K. Pronunciation instruction for Brazilians: bringing theory and practice together. [s.I.]: Cambridge Scholars Publishing, 2009. 